\title{
Komitmen Lingkungan dan Budaya CSR \\ Kreatif Multitema Batik Alam Malon \\ PT Indonesia Power Semarang Power Generation Unit
}

Darmawan Hendro S.

Supervisor Senior Keamanan dan Humas, PT Indonesia Power Semarang PGU darmawan_amel@yahoo.comt

Agus Naryoso

Dosen, Departemen Ilmu Komunikasi FISIP Undip dan

Dosen Prodi D3 Humas, PSDKU Batang, Universitas Diponegoro

agusnaryoso@gmail.com

\begin{abstract}
Kegiatan Tanggung Jawab Sosial Perusahaan (CSR) dilakukan tidak hanya untuk kepatuhan hukum atau menjalankan mandat hukum. Tanggung Jawab Sosial Perusahaan (CSR) tidak hanya rekomendasi dari pemerintah kepada pelaku bisnis tetapi juga kewajiban yang harus dilaksanakan oleh perusahaan baik swasta dan pemerintah. UU No. 40/2007 mengamanatkan bahwa semua perusahaan mengalokasikan dana dari hasil bisnis untuk kegiatan sosial sebagai bentuk komitmen terhadap lingkungan sekitar. PT Indonesia Power Unit Pembangkit Listrik Semarang secara konsisten merespons dan melaksanakan kewajiban ini. Kewajiban ini dilakukan bukan untuk menghindari sanksi dan teguran pemerintah tetapi sebagai upaya menyeimbangkan dan menyelaraskan kepentingan bisnis perusahaan dengan komitmen terhadap lingkungan, kemandirian ekonomi, dan upaya pelestarian budaya. Makalah ini menggunakan jenis penelitian deskriptif dengan pendekatan analisis audit komunikasi. Pengumpulan data dilakukan dengan mewawancarai berbagai sumber yang relevan dari kalangan internal dan juga penerima manfaat dari kegiatan CSR Multitema di Batik Alam Malon, Kecamatan Gunungpati, Kota Semarang.
\end{abstract}

Kata Kunci: CSR, Batik, Lingkungan, Budaya

\section{Pendahuluan}

Tanggung jawab sosial dan lingkungan masyarakat.

perusahaan adalah bentuk bentuk dan Kegiatan Corporate Social

kontribusi perusahaan untuk Responbility (CSR) yang dilakukan

keberlangsungan dehidupan diharapkan menjawab dan memeni

masyarakat disekitarnya, kegiatan kebutuhan masyarakat serta memiliki

tersebut untuk menunjukkan banyak dampak positif terhadap

komitmen pada isu sosial, ekonomi perusahaan yaitu dapat 
mempertahankan atau mendongkrak reputasi agar mendapatkan kepercayaan publik yang tinggi serta mampu membangun identitas merek perusahaan yang kuat, perusahaan yang mempunyai kesadaran melaksanakan kegiatan CSR dengan baik sudah selayaknya mendapatkan kesempatan luas dan dukungan yang kuat untuk terus melaksanakan operasional bisnisnya dengan baik, komitmen dan dukungan tersebut akan datang dari berbagai stakeholder komunitas, pemerintah lokal serta pemilik saham. Regulator akan memberikan pengakuan akan kredibilitas lembaga bisnis tersebut karena taat hukum dan beretika bisnis yang baik, maka kegiatan Corporate Social Responbility (CSR) merupakan hal penting bagi keberlangsungan suatu perusahaan untuk kepentingan publik.
CSR dalam jangka panjang akan memberikan garansi bisnis yang menguntungkan, tidak hanya meningkatkan kepercayaan publik, memperkuat investasi, namun pelaksanaan kegiatan CSR dipastikan akan mengamankan operasi bisnis perusahaan sehingga perusahaan dapat menjalankan operasional tanpa kendala yang muncul dari lingkunga terdekat. Undang - Undang Perseroan Terbatas No. 40 Tahun 2007. Pasal 74 ayat (1) berbunyi demikian : "Perseroan yang menjalankan kegiatan usahanya dibidang atau berkaitan dengan Sumber Daya Alam wajib melaksanakan Tanggung Jawab Sosial dengan Lingkungan." (Rahmatullah dan Kurniati,2011:18). PT Indonesia Power Semarang Power Generation Unit, sebagai perusahaan pelat merah secara sadar merespon anjuran atau kewajiban pemerintah tersebut secara positif. Kegiatan CSR 
dilakukan direncanakan sebagai lingkungan, nilai, norma, dan budaya bagian dari program startegis masyarakat setempat. Perusahaan manajemen, tidak hanya sekedar perlu merespon dengan baik, serta kegiatan untuk menunjukkan pada melihat permsalahan sosial yang publik telah melakukan kegiatan belum tertangani dengan baik, CSR, namun alokasi bantuan yang melalui kegiatan CSR perusahaan diberikan harus benar-benar mampu bermitra dengan pemerintah membantu mengatasi problematika membantu mengentaskan lingkungan sekitar dan menciptakan kemiskinan, menciptakan kemandirian target sasaran.

Konsep dan tujuan CSR yang dilakukan senada dengan Siti Kotijah (2008) dalam (Prastowo dan Huda 2011:48) bahwa tanggung jawab sosial dan lingkungan bertujuan mewujudkan pembangunan ekonomi berkelanjutan guna meningkatkan kualitas kehidupan dan lingkungan yang bermanfaat bagi perseroan itu sendiri, komunitas setempat dan masyarakat pada umumnya. Hal ini dalam rangka mendukung terjalinnya hubungan perseroan yang serasi, seimbang dan sesuai dengan kemandirian warga, bekerjsama dan berkomitmen menjaga keseimbangan lingkungan serta peduli terhadap kelestarian budaya lokal.

Sebagai perusahaan yang memiliki niat dan kesungguhan yang tinggi, serta menyadari posisi menggunakan wilayah area operasi Bisnis Kota Semarang, PT Indonesia Power Semarang Power Generation Unit berkomitmen membantu mengatasi pengentasan kemiskinan dengan membantu menyediakan fasilitas permodalan. Kecamatan Gunungpati adalah salah 
satu dari 16 Kecamatan yang ada di

Kota Semarang, data demografis menunjukkan angka kemiskinan di wilayah ini relatif tinggi. Seperti dikutip dari hasil riset yang dlakukan oleh Lembaga Penelitian dan Pengabdian pada Masyarakat Unisbank Semarang (2008) Profil masyarakat miskin di 4 kecamatan Pedurungan, Semarang Utara, Semarang Barat dan Gunungpati adalah sebagai berikut : jenis pekerjaan meliputi buruh, wiraswasta dan nelayan, dengan besar penghasilan di bawah Rp.500.000,perbulan. Usia termasuk usia produktif, jumlah anggota keluarga 2

-5 orang, tingkat pendidikan rendah yaitu lulus sekolah dasar, menggunakan air dari sumur, menggunakan tenaga listrik, kebutuhan akan tempat tinggal dipenuhi sendiri, tidak memiliki tanah garapan serta masyarakat di lingkungan sekitar bekerja sebagai buruh.

$\begin{array}{ccc}\text { Realitas } & \text { tersebut diatas } \\ \text { menunjukkan } & \text { bahwa angka }\end{array}$
kemiskinan yang tinggi masih cukup dominan di Kota Semarang, fakta ini memerlukan kesadaran berbagai stakeholder untuk membantu mengentaskan kemiskinan melalui berbagai program bantuan ekonomi, tanggung jawab sosial perusahaan maupun pemberdayaan masyarakat. Wuryani dan Wahyu (2012: 149) menyatakan bahwa pemberdayaan merupakan bentuk dari proses perubahan sosial menuju ke arah masyarakat yang hidup lebih baik dan sejahtera. Konsep tersebut diatas sejalan dengan kebijakan perusahaan untuk mengedepankan bantuan yang tidak bersifat konsumtif, namun lebih pada upaya untuk mendorong kemandirian ekonomi masyarakat Kecamatan Gunung pati agar dapat 
mengatasi permasalahan ekonomi sendiri.

\section{Metode Penelitian}

Tipe penelitian dalam penelitian ini kualitatif. Penelitian kualitatif memiliki sejumlah sifat antara lain menangkap dan menemukan makna ketika peneliti terlibat dalam data. Konsep muncul dalam bentuk tematema, motif-motif, generalisasi, taksonomi. Pengukuran dilakukan secara sementara dan seringkali spesifik pada latar individu atau peneliti. Data dalam bentuk kata-kata dari dokumen, observasi, dan transkrip. Teori bisa bersifat kausalistik maupun non kausalistik serta seringkali induktif. Prosedur riset cenderung khusus dan jarang muncul replikasi. Proses analisis dilakukan dengan cara menyarikan tema atau generalisasi dari bukti dan mengelola data dilakukan untuk menyajikan gambaran yang koheren dan konsisten (Neuman,1997). Penelitian yang dilakukan merupakan jenis penelitian kualitatif yang menggunakan pendekatan audit komunikasi, dengan melakukan evaluasi pada tahapan tahapan pelaksanaan kegiatan CSR Kreatif Multitema Batik Malon oleh PT Indonesia Power Semarang Power Generation Unit. Wawancara dilakukan secara mendalam dengan pelaksana kegiatan CSR level manajer, sampai ke Pelaksana, dan untuk mengkonfirmasi data juga dilakukan wawancara dengan penerima manfaat dan pakar CSR.

\section{Tinjauan Pustaka}

Kegiatan CSR idealnya mampu menjadikan masyarakat untuk bergerak dan mempunyai motivasi yang tinggi untuk memiliki kehidupan yang lebih maju dan 
berkembang. Kehadiran lembaga pemberi bantuan adalah fasilitator dan pendampingan manajemen, bukan lembaga pemberi bantuan materi, tanpa masyarakat melakukan usaha apapun. "Community empowerment is a term describing a participative and developmental approach to local decision making, "through which marginalized or oppressed community members and groups acquire valued resources and basic rights, and achieve greater control over their lives and environment" (Yulong and Caroline, 2015: 249). Mengacu pada konsep diatas, perusahaan mendorong dan memberika bantuan agar target sasaran mmepunyai motivasi yang tinggi, melihat potensi sekitar dan melakukan usaha untuk keluar dari kemiskinan. Masyarakat setempat di dorong untuk mengetahui potensi yang besar di sekitar lingkungan mereka dan memanfaatkannya secara produktif. Masyarakat perlu diajarkan untuk mengenal bisnis dan wirausaha, dengan melihat sumber daya yang dimiliki serta peluang pasar yang prospektif. Tidak hanya berhenti disitu, Konsep stakeholder merupakan faktor inti dalam kajian CSR, Stakeholder adalah Para pemangku kepentingan atau dapat didefinisikan sebagai kelompok dan individu yang dapat mempengaruhi atau dipengaruhi oleh, pencapaian misi organisasi (Freeman, 1984 : 54) atau sebaliknya kelompokkelompok yang memiliki kepentingan pada perusahaan (Evan \& Freeman, 1988 : 97).

CSR mendukung hubungan baik dengan para pemangku kepentingan seperti karyawan, konsumen, investor, Pemerintah (Mictell et al., 1997). Harapan, tuntutan dan kebutuhan stakeholder yang dipenuhi 
melalui kegiatan CSR akan Pada tanggal 8 Oktober 2000, PT PJB

mempengaruhi terbentuknya reputasi

perusahaan yang baik (Donaldson dan

Preston 1995). Teori stakeholder yang

berkaitan dengan CSR

mengantisipiasi dampak buruk

masalah kapitalisme dan etika bisnis

(Parmar et al . 2010, p . 413). Phillips

(2003) memperkenalkan konsep

legitimasi stakeholder, bahwa CSR

mengidentifikasi kebutuhan dan

kondisi normatif para pemangku

kepentingan, mengurangi dampak

kapitalisme dan etika bisnis

organisasi (Parmar et al . 2010, p .

413).

\section{Hasil dan Pembahasan}

PT Indonesia Power

merupakan salah satu anak

Perusahaan PT PLN (Persero) yang

didirikan pada tanggal 3 Oktober

1995 dengan nama PT PLN

Pembangkitan Jawa Bali I (PT PJB I).
I berganti nama menjadi

PT

Indonesia Power sebagai penegasan atas tujuan Perusahaan untuk menjadi

Perusahaan pembangkit tenaga listrik independen yang berorientasi bisnis murni.

Kegiatan utama bisnis Perusahaan saat ini yakni fokus sebagai penyedia tenaga listrik melalui pembangkitan tenaga listrik dan sebagai penyedia jasa operasi dan pemeliharaan pembangkit listrik yang mengoperasikan pembangkit yang tersebar di Indonesia. Berawal pada pengelolaan Pembangkit Listrik di Jawa Bali, saat ini PT Indonesia Power telah melakukan Pengembangan Bisnis Jasa Operasi Pemeliharaan di seluruh Indonesia baik melalui pengelolaan sendiri, maupun melalui Anak Perusahaan.

PT Indonesia Power mengelola 4 Power Generation Unit 
(PGU), serta 5 Power Generation and

O\&M Services Unit (POMU), 12

Operation and Maintenance Services

Unit (OMU), 1 dan 1 Unit

Maintanance Service Unit (MSU). PT

Indonesia Power Semarang Power

Generation Unit

(PGU)

mengoperasikan Pusat Listrik Tenaga

Gas (PLTG), Pusat Listrik Tenaga

Gas \& Uap (PLTGU) dan Pusat

Listrik Tenaga Uap (PLTU) yang

berlokasi di Semarang Jawa Tengah,

Pusat Listrik Tenaga Gas (PLTG)

Lomanis Cilacap, Pusat Listrik

Tenaga Gas (PLTG) Sunyaragi

Cirebon dan Pusat Listrik Tenaga

Diesel (PLTD) Legon Bajak

Karimunjawa. PT Indonesia Power

Semarang Power Generation Unit

memiliki total kapasitas sebesar

1233.9 MW memegang peranan yang

penting dalam menjaga keandalan

dan mutu sistem kelistrikan Jawa Bali

terutama Jawa Tengah.
PT Indonesia Power sesuai

misinya "Menyediakan Solusi Energi

yang andal, Inovatif, Ramah Lingkungan dan Melampaui Harapan Pelanggan" melakukan aksi nyata terhadap pengelolaan lingkungan yaitu ikut serta dalam membuat project konsep jamban di Kabupaten Wonosobo dengan jumlah 1.600 jamban keluarga. PT Indonesia Power Semarang Power Generation Unit juga meluncurkan anggaran CSR hingga 217 juta pada tri wulan IV 2017. CSR ini disalurkan melalui kelompok unggulan binaan diantaranya budi daya mangrove dan ikan bandeng serta kampung batik alam malon Gunungpati. PT Indonesia Power Semarang Power Generation Unit berkomitmen untuk mengembangkan UKMKM untuk terus menggali potensinya sehingga bisa menciptakan kreasi yang berdampak positif bagi 
perekonomian, tidak hanya berhenti pada satu tujuan, PT. Indonesia Power Semarang Power Generation Unit juga memfasilitasi pameran batik Semarang Micro Finance sebagai langkah membantu pemasaran produk perekonomian mandiri mitra binaan.

Corporate Social Responsibility (CSR) adalah bentuk goodwill perusahaan dalam membangun hubungan baik dengan masyarakat pemangku kepentingan sehingga akan berdampak pada keuntungan nonmaterial yang mendapatkan keuntungan dari proses investasi jangka panjang.

Banyak pelaku bisnis yang melakukan Corporate Social Responsibility (CSR) mempertimbangkan lebih pada ekonomi dibandingkan dengan motif sosial dan lingkungan. Namun orientasi yang hanya berfokus pada memperoleh keuntungan finansial sering membuat kegiatan ini dilakukan tanpa perencanaan yang matang, dana yang dialokasikan relatif kecil akan cenderung menjadi sia-sia dengan tidak mempertimbangkan pemberdayaan berkelanjutan.

Kegiatan pelaksanaan

Corporate Social Responsibility (CSR) dan prosedur yang diatur dengan menggunakan Surat Keputusan Direksi Nomor 25.K / 010 / IP / 2014 Mengenai Pedoman Tanggung Jawab Sosial dan Lingkungan Perusahaan dan Surat Keputusan Direksi Nomor 26.K / 010 / IP / 2014 mengenai Pedoman Pelaksanaan Inpower-Care di Lingkungan PT. Indonesia Power. Maksud dan tujuan dari keputusan tanggung jawab sosial dan lingkungan adalah untuk mewujudkan visi dan misi perusahaan, terutama untuk ramah 
lingkungan dan realisasi bidang ekonomi dan pelatihan pemerintahan yang baik dalam bentuk kontribusi nyata untuk pembangunan berkelanjutan, memberikan dukungan untuk kesuksesan bisnis jangka panjang, memenuhi harapan pemangku kepentingan terhadap perusahaan, menyelaraskan aktivitas perusahaan dengan norma-norma hukum yang berlaku dan undang-undang.

Kampung Batik Alam Malon, Gunungpati Program Batik Alam berlokasi di Kampung Malon, Gunungpati, Semarang. Kegiatan CSR ini berupa pelatihan pembuatan batik, wirausaha batik lokal, dan bazar serta pameran yang rutin diadakan. PT Indonesia Power Semarang Power Generation Unit membantu mengembangkan dan membina pembuat batik dan warga sekitar Kampung Malon dalam

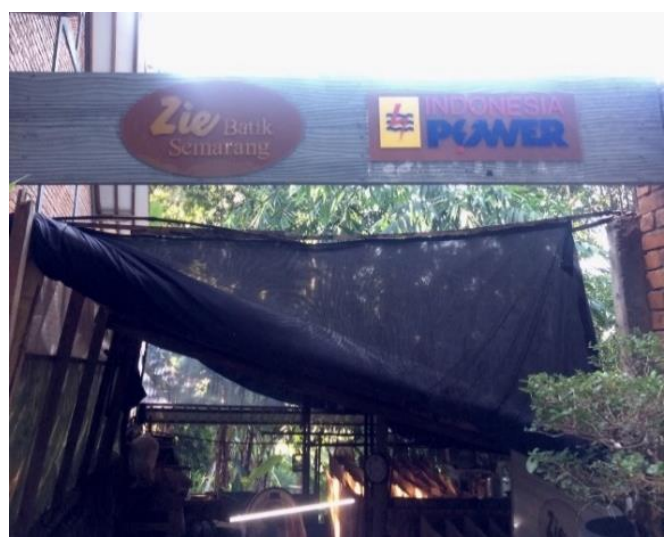

Gambar 2 : Workshop Batik Zee Mitra Binaan Utama

Zie batik merupakan salah satu usaha binaan dari PT Indonesia Power Semarang Power Generation Unit yang terletak di Kampung Malon, Gunungpati Semarang. Dalam menjalankan usahanya Zie Batik 
konsisten dalam menjaga kelestarian

alam dengan menggunakan bahan-

bahan alami dari alam untuk

pembuatan batik, hal ini sejalan

dengan visi misi PT Indonesia Power

Semarang Power Generation Unit

dalam menjalankan bisnis yang

bersahabat dengan lingkungan. Zie

batik sudah dibina oleh Indonesia

Power sejak tahun 2014 hingga saat

sekarang ini. Zie Batik yang

merupakan pendatang di Kampung

Malon juga mengajak ibu-ibu sekitar

untuk ikut serta menekuni bisnis ini

dan berhasil mendorong munculnya

UMKM Batik lain seperti Citra Batik,

Manggis batik, Delima Batik yang

diketuai oleh Umi Salamah pemilik

Salma Batik.
Kegiatan CSR yang dilakukan

dalam bentuk inisiasi pendirian dan pembinaan kampung Batik Malon tersebut diharapkan akan menghasilkan potensi ekonomi besar, dimana satu kampung menekuni bisnis batik ramah lingkungan yang menggunakan pewarna alami yang diambilkan dari bahan bahan alami tumbuh tumbuhan yang banyak tersedia di Gunungpati. Salah satu Pelatihan pembuatan ecoprint bersama warga kampung malon di galer zie batik salah satu UMKM Mitra Binaan yang sudah sukses mengembangkan batik alam malon dengan pewarna alam. Pelatihan membuat Batik Ecoprint adalah teknik membatik dengan memanfaatkan motif daun, ranting pohon, akar dan kulit pohon menjadi pola untuk menciptakan sebuah lukisan dalam kain polos yang 
kemudian di siram dengan Dalam upaya untuk lebih

menggunakan pewarna alami.

Teknik diatas merupakan

metode alternatif lain untuk mengghasilkan karya batik dengan desain yang inovatif dan berbeda dengan batik lainnya. Latar belakang dari metode ini adalah memanfaatkan kearifan lokal potensi sumber daya alam di sekitar Gunungpati yang merupakan daerah dengan mayoritas wilayah hutan.

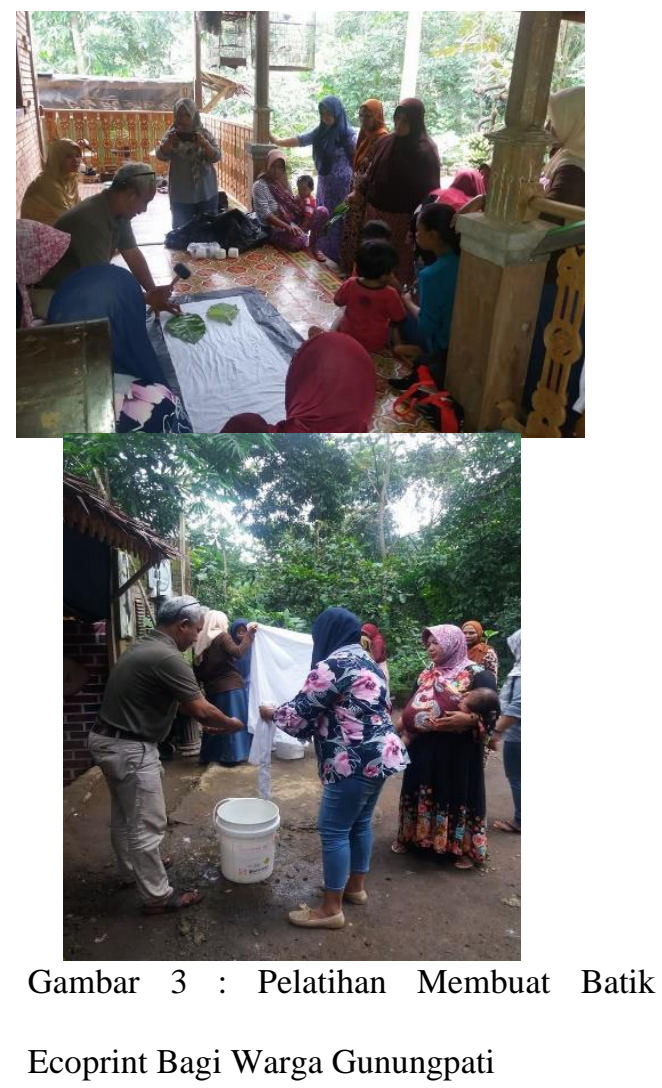

ACTA DIURNA | VOL. 16 NO. 1 | 2020 memperkenalkan Batik khususnya Batik Alam Malon ke market yang lebih luas, UMKM Binaan juga membuat program Kunjungan turis belajar membatik, Pogram ini merupakan kerjasama Institusi dengan dengan dunia pendidikan Universitas Katolik Soegijapranata, dimana berdasarkan koordinasi dengan PT Indonesia Power Semarang Power Generation Unit Selaku fasilitator pembinaan UMKM Batik Alam Malon dengan perguruan tinggi yang akan melakukan kegiatan pengandian masyarakat. Inisiatif dari pihak perguruan tinggi tinggi perlu direspon positif, mengingat kedua institusi mempunyai semangat yang sama yakni pengentasan kemiskinan dengan mendukung usaha yang bernilai ekonomi tinggi, berkomit pada lingkungan yang anti polisi dan 


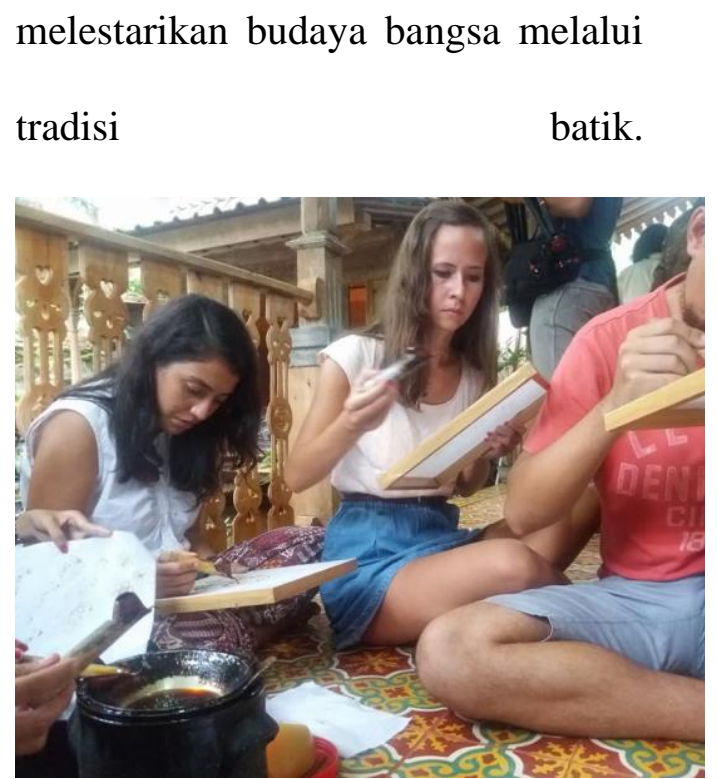

Gambar 4 : Pelatihan Membatik

Ecoprint Bagi Wisatawan

Mancanegara

Pelatihan membatik ecoprint bagi wisman adalah upaya promotif agar batik memiliki nilai jual dan diminati oleh masyarakat asing, harapannya kegiatan tersebut memiliki nilai strategis agar Batik Alam Malon lebih mendunia dan meningkatkan omset pemasaran. Melalui kegiatan tersebut, wisman diharapkan akan mencintai tradisi membatik dan juga mengedukasi tentang batik yang tidak menggunakan bahan kimia sebagai pewarna tetapi menggunakan pewarna alami yang ramah lingkungan . Untuk menjaga kualitas CSR agar selalu memenuhi kebutuhan sasaran dan kepentingan bisnis, perusahaan rutin menggelar event CSR Multi stakeholder setiap tahun yang di koordinatori oleh divisi penanggung jawab CSR.

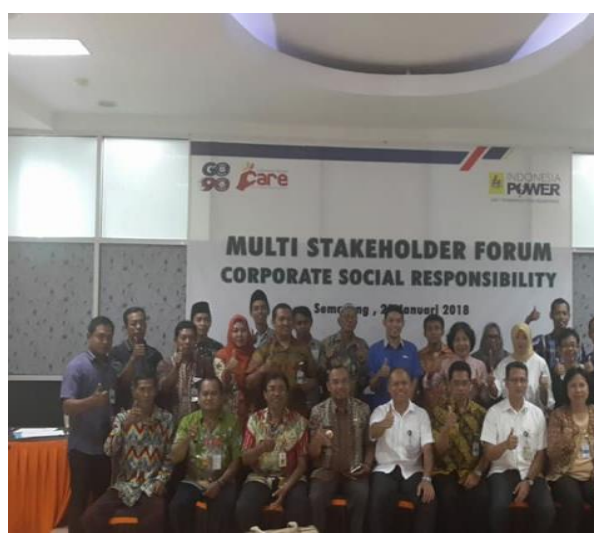

Gambar 5 : CSR Multisatkeholder Forum yang diikuti penerima manfaat, pemerintah dan akademisi

Acara ini menjadi sangat strategis untuk melihat apakah kegiatan CSR yang dilakukan mencapai hasil yang dinginkan, dalam kegiatan ini di hadirkan penerima manfaat, pemerintah lokal, fasilitator dan juga akademisi yang akan mengkritisi dan memberikan 
masukan agar kegiatan CSR lebih meningkat kualitasnya. Acara ini juga merupakan media untuk memberikan pelaporan kepada pemerintah lokal tentang kegiatan dan kontribusi perusahaan pada masalah dan isu lokal. Harapannya agar perusahaan mendapatkan pengakuan atas komitmen dan kepatuhanny amelaksanakan perintah undangundang. Kegiatan yang dilakukan adalah media komunikasi untuk bisa menganalisis kesenjangan kebutuhan dengan program yang ditawarkan, hal tersebut dimaksudkan untuk menyempurnakan pelaksanakaan kegiatan CSR periode mendatang agar jauh lebih baik dan efektif mencapai tujuan kedua belah pihak.

Berbicara tentang motif atau latar belakang keputusan melaksanakan kegiatan sangat beragam tergantung perspektif masing-masing perusahaan pemberi bantuan. Beberapa perusahaan melaksanakan karena menjunjung tinggi aspek hukum atau amanat undang-undang, namun ada juga yang menggunakan CSR sebagai salah satu bentuk kompensasi etika bisnis.

Tabel 1

Spectrum Of Viewpoints On The Role Of Business In Society Source: Adapted From Lantos (2001, P. 602)

\begin{tabular}{|l|l|l|}
\hline No & \multicolumn{1}{|c|}{ Teori/Pandangan } & \multicolumn{1}{c|}{ Posisi Bisnis di Masyarakat } \\
\hline 1 & Classical & $\begin{array}{l}\text { 1. Murni Berorientasi mencari keuntungan } \\
\text { 2. Bisnis menjadi standar utama daripada etika } \\
\text { pada masyarakat } \\
\text { 3. Tidak ada kewajiban melakukan } \\
\text { tanggungjawab sosial selain hanya } \\
\text { kepatuhan kepada hukum }\end{array}$ \\
& & $\begin{array}{l}\text { 4. Bisnis memaksimalkan keuntungan besar } \\
\text { pemegang saham }\end{array}$ \\
\hline 2 & Stakeholder & $\begin{array}{l}\text { 1. Kesadaran yang tinggi tentang bisnis harus } \\
\text { peka pada kebutuhan para pemangku } \\
\text { kepentingan }\end{array}$ \\
\hline
\end{tabular}




\begin{tabular}{|l|l|}
\hline & $\begin{array}{l}\text { 2. } \begin{array}{l}\text { CSR dipergunakan mengantisipasi } \\
\text { kemungkinan bahaya yang muncul dari } \\
\text { stakeholder }\end{array} \\
\text { 3isnis harus memaksimalkan sumber daya } \\
\text { yang dimiliki untuk invesatsi sosial }\end{array}$ \\
\hline
\end{tabular}

PT. Indonesia Power melaksanakan kegiatan CSR tidak semata mata berorientasi pada upaya mencari keuntungan finansial. Sebagai perusahaan penyuplai energi listrik, tidak ada relevansinya secara langsung antara dana yang dikucurkan untuk kegiatan CSR dengan perolehan pendapatan secara langsung. Perspektif stakeholder melatarbelakangi dan menjadi motif utama strategi CSR di perusahaan ini. Komunitas dan pemerintah lokal adalah mitra utama yang sangat strategis bagi Indonesia Power, keberadaan, sikap dan respon mereka mempengaruhi performa operasional perusahaan. Kebutuhan ekonomi yang mendesak, program yang berorientasi pada ramah lingkungan, serta kewalahan pemerintah mengentaskan kemiskinan harus di bantu oleh segenap stakeholder yang terkait, lebih lebih yang berlokasi di daerah tersebut. Freeman (1984); Dan Golob Dan Barlett (2007) menemukan bahwa terdapat tanggung jawab timbal balik antara Bisnis dan masyarakat, pemangku kepentingan. Teori stakeholder, Menurut Freeman (1984); Dan Golob Dan Barlett (2007) dalam (Chai Lee Goi). Konsep tersebut menunjukkan bahwa terdapat berbagai Kelompok di Lingkungan sosial yang mempunyai pengaruh kuat terhadap organisasi, fokus teori ini menekankan pentingnya bisnis memahami Stakeholder seperti masyarakat Lokal, hubungan tata kelola Perusahaan dengan Dampak Lingkungan , karyawan , pelanggan Dan Pemasok, Pemegang Saham Dan 
Pemerintah. Hal tersebut menjadi tanggung jawab utama PR dalam bentuk Menjaga komunikasi yang baik dengan berbagai publiknya. Perusahaan ini berasumsi melalui CSR akan memberikan dukungan berarti dan besar agar perusahaan terus konsisten dan produktif dengan pengertian yang baik dan sikap saling menguntungkan antara organisasi dengan publik. Model evaluasi keberhasilan kegiatan CSR menurut Assessment Factors by Corporate Citizenship Company (Yakovleva 2005, 23) dalam Emily A. Coleman (2011) dapat dilihat dari beberapa elemen :

Tabel .2 : Evaluasi CSR

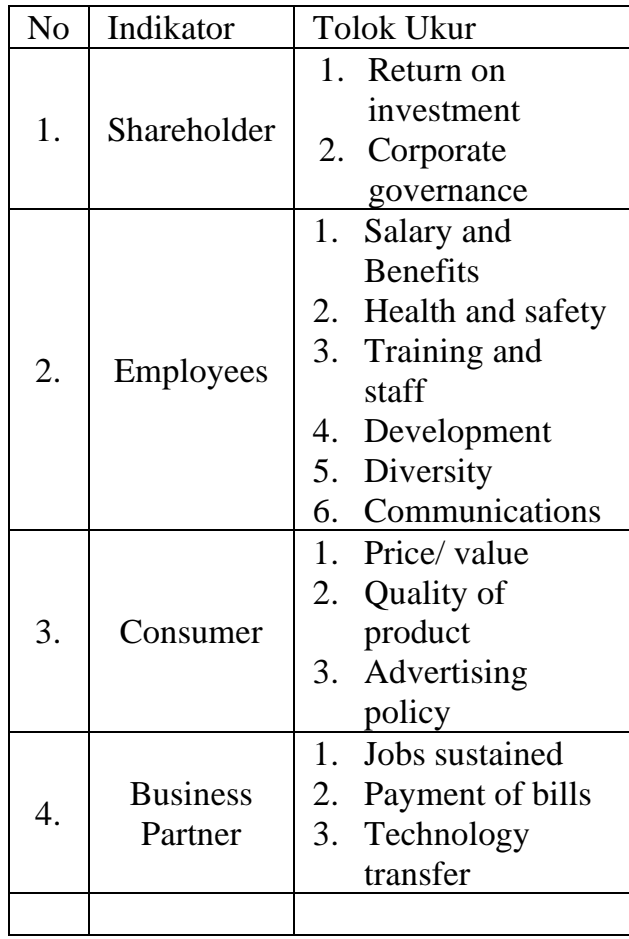

\begin{tabular}{|c|c|c|}
\hline $\mathrm{No}$ & Indikator & Tolok Ukur \\
\hline 5. & Government & $\begin{array}{l}\text { 1. Tax contribution } \\
\text { 2. Local economic } \\
\text { impact } \\
\text { 3. Transfer pricing } \\
\text { policies }\end{array}$ \\
\hline 6. & Community & $\begin{array}{l}\text { 1. Charity } \\
\text { contributions } \\
\text { 2. Local economic } \\
\text { impact } \\
\text { 3. Transfer pricing } \\
\text { policies }\end{array}$ \\
\hline 7. & Environment & $\begin{array}{l}\text { 1. Sustainable raw } \\
\text { materials } \\
\text { 2. Emissions to } \\
\text { water and air } \\
\text { 3. Energy efficiency } \\
\text { 4. Waste } \\
\text { management } \\
\text { 5. Reduced } \\
\text { packaging } \\
\text { 6. Consumer } \\
\text { education }\end{array}$ \\
\hline
\end{tabular}

Tabel diatas menjadi patokan untuk mengukur dan melakukan audit perusahaan pemberi bantuan CSR bagi masyarakat sasaran. PT Indonesia Power Semarang Power Generation Unit dalam prakteknya telah memberikan manfaat besar dengan Program CSR Kreatif 
Multitemanya bagi masyarakat kriminalitas. Lebih dari itu tujuan Gunungpati Semarang, setidaknya utama yang ingin dicapai melalui ada tiga kelompok yang sangat kegiatan investasi sosial ini adalah terbantu dengan inisiatif yang relasi yang baik dengan pemerintah dilakukan oleh PT. Indonesia Power lokal sebagai pemilik atau otoritas Semarang Power Generation Unit. tempat operasional perusahaan.

Pertama adalah dampak atau Keuntungan besar juga manfaatnya bagi pemerintah, bahwa kegiatan tersebut seiring dengan rencana strategis Pemerintah Kota Semarang untuk menekan atau mengurangi tingginya angka kemiskinan yang di tandai dengan penghasilan yang rendah dan banyaknya pengangguran. Melalui program ini akan lahir banyak UMKM yang berbasis produksi Batik Alam Malon, hal tersebut membuka peluang kerja dan mengurangi pengangguran. Masyarakat dapat menambah pemasukan keluaga melalui bsnik batik alam ini. Selain itu rendahnya angka pengangguran juga meminimalisasi kasus 
dukungan manajemen pemasaran batik dan usaha lainnya, pemasaran. Kebijakan tersebut sehingga akan bergerak bersama diambil untuk memangkas dan membangun kemajuan ekonomi mengantisipasi penggunaan dana lokal.

untuk kegiatan di luar usaha CSR yang dilakukan pengembangan batik alam malon. sengaja di desain dengan Target utama dari bantuan yang menggunakan pertimbangan beda diberikan ke wilayah Gunungpati dari CSR yang kebanyakan dilakukan Semarang lebih pada upaya oleh perusahaan lainnya, tentunya pemberdayaan masyarakat sehingga tetap memperhatikan kebutuhan ekonomi setempat akan tumbuh masyrakat penerima bantuan. dengan baik. Selain itu juga untuk Kebanyakan perusahaan hanya mendukung pengembangan wisata berfokus pada peningkatan daerah tersebut agar mempunyai pendapatan sementara keberlanjutan cenderamata yang khas bagi keseimbangan lingkungan tidak wisatawan yang berkunjung. Batik diperhatikan, banyak daerah Alam Malon kualitas selalu terus lokasinya berkembang menjadi pusat diupayakan mulai dari bahan dasar, ekonomi yang maju, namun desain dan juga keterjagangkauan masyarakat sekitarnya hidup harga. Berkembangnya industri batik berdampingan dengan lingkungan alam malon didorong juga mampu yang tercemar, padahal disisi yang mengembangkan sektor mikro lain pencemaran tersebut akan lainnya seperti penyuplai kain dasar, berdampak pada kualitas kesehatan usaha pewarna alam, distributor masyarakat setempat. Kegiatan ini 
juga didesain untuk pelestarian budaya lokal, melalui Batik publik dan konsumen terus di edukasi agar menyukai batik sebagai salah satu pilihan trend fashion khususnya bagi anak muda.

Penelitian tentang tren dan pola public relations berkaitan dengan Corporate Social Responsibility (CSR) dipublikasikan antara tahun 1998 dan 2007 menunjukkan bahwa PR bahwa perkembangan praktik CSR telah mengalami kemajuan yang pesat bahwa CSR bagian dari manajemen komunikasi, seperti yang diusulkan oleh Clark (2000), salah satu fungsi PR adalah menggabungkan fungsi manajemendan komunikasi Temuan menunjukkan bahwa ada peluang untuk memasukkan kegiatan tanggung jawab sosial perusahaan ke dalam program yang berkaitan dengan hubungan ke stakeholder melalui pendekatan proses, yang akan membina hubungan yang lebih kuat antara organisasi, stakeholder dan masyarakat. CSR dapat membantu perusahaan dalam merumuskan nilainilai terhadap peningkatan tanggung jawab kemanusiaan dan corporate citizenship.

\section{CSR Secara strategis} dilakukan oleh PT Indonesia Power Semarang Power Generation Unit diarahkan untuk membangun dukungan publik yang kuat pada bisnis yang dilakukan oleh perusahaan tersebut. Mengurangi protes komunitas lokal, meminimalisasi pengrusakan dan pencurian aset, menghindari prasangka pada pencemaran lingkungan serta menghilangkan tudingan melakukan bisnis yanng tak beretika merupakan bagian dari kebijakan yang melatarbelakangi kegiatan CSR, sikap positif publik 
menghasilkan reputasi yang kuat

bisnis perusahaan. Reputasi yang kuat

akan menumbuhkan kepercayaan

kelompok berpengaruh yang lebih

besar yakni pemengang saham, calon

investor dan juga pemerintah lokal.

\section{Kesimpulan}

Kegiatan Corporate Social

Responsibility (CSR) dilakukan tidak hanya semata mata untuk kepatuhan hukum atau menjalankan amanat

Undang Undang, namun lebih dari itu yaitu memberikan dampak besar bagi peningkatan kapasitas ekonomi lokal.

Kegiatan CSR yang dilakukan oleh PT Indonesia Power Semarang Power Generation Unit tidak hanya berfokus pada satu kegiatan saja seperti pemberian bantuan permodalan alat usaha produksi Batik, namun usaha

\section{Daftar Pustaka}

Coleman, Emily A. (2011). An Evaluation of Corporate Social Responsibility Initiatives Implemented by Alcoa, Votorantim, and Vale as a Means tersebut juga diarahkan untuk membantu menciptakan keseimbangan lingkungan, dimana bisnis tidak meninggalkan pencemaran. Pemilihan pewarna alam adalah upaya untuk mengantisipasi pencemaran yang seringkali banyak ditinggalkan dan kurang diperhatikan oleh pengusaha batik. Penggunaan pewarna kimia di hindari agar tidak banyak lingkungan yang tercemar dan menganggu kualitas kesehatan masyarakat sekitar. Selain itu produksi Batik Alam Malon juga menjadi media untuk mempertahakan kearifan dan budaya lokal. Batik di dorong untuk terus berkembang menjadi alternatif trend fashion yang diminati oleh semua kelompok segmen khususnya anak muda.

to Aid in Poverty Alleviation in the Brazilian Regions These Mining Companies Operate. CMC Senior Theses. Paper 198. Retrieved February 23, 2018, from 
http://scholarship.claremont.edu/ cmc_theses/198

Evan, W. M., \& Freeman, R. E. 1988. A stakeholder theory of the modern corporation: Kantian capitalism. In T. Beauchamp \& N. Bowie (Eds.), Ethical theory and business: 75-93. Englewood Cliffs, NJ: Prentice Hall.

Goodwin, Felicity W. \& Bartlett, Jennifer L. (2008), Public Relations and Corporate Social Responsibility (CSR) - Working Paper http://eprints.qut.edu.au/view/pe rson/Bartlett,_Jennifer.html. Access on on April 182015

Lantos, G. P. (2001) "The boundaries of strategic corporate social responsibility", Journal of Consumer Marketing, Vol. 18 No. 7, pp. 595-630.

Lembaga Penelitian dan Pengabdian pada Masyarakat Unisbank Semarang (2008). Studi Pemetaan Kemiskinan di Kota Semarang, Riptek,Vol. Itahun 2008 Hal 35-39

Neuman, W.L. 1997. Social Research Method Qualitatif and Quantitatif Approaches. 3rd edition. Boston Pearson education.

Parmar, B. L., Freeman, R. E., Harrison, J. S., Wicks, A. C., Purnell, L., and de Colle, S. (2010). Stakeholder theory: The state of the art. Academy of Management Annals, 4, 403-45
Prastowo, Joko., dan Huda, Miftachul., (2011), Corporat Social Responsibility Kunci Meraih Kemuliaan Bisnis, cetakan pertama, Samudra Biru, Yogyakarta.

Rahmatullah Dan Kurniati, Trianita. 2011. Panduan Praktis Pengelolaan CSR (Corporate Social Responsibility). Padeglang Dan Depok: Samudera Biru.

Undang - Undang Republik Indonesia No. 40 tahun 2007 dan Peraturan Presiden RI Tahun 2014 Tentang Perseroan Terbatas

Wuryani, Emy dan Wahyu Purwiyastuti. 2012. Menumbuhkan Peran Serta Masyarakat Dalam Melestarikan Kebudayaan Dan Benda Cagar Budaya

Melalui Pemberdayaan

Masyarakat Di Kawasan Wisata

Dusun Ceto. Satya

Widya, Vol. 28, No.2. Universitas Kristen Satya Wacana

Yulong, Li dan Caroline Hunter. 2015. "Community involvement for sustainable heritage tourism: a conceptual model", Journal of Cultural Heritage Management and Sustainable Development, Vol. 5 Issue: 3, pp.248-262. Tersedia (online) https://doi.org/10.1108/JCHMS D-08-2014-0027. Diakses pada 21 Juli 2018 pukul 10:18 WIB.

\section{Penulis}

1. Darmawan Hendro $S$.

Adalah Supervisor Senior Keamanan dan Humas PT Indonesia Power Semarang PGU, menjabat posisi tersebut dari 2015 - Sekarang, mempunyai focus pada bidang Community Development / CSR, kehumasan dan keamanan, trainer dalam ISO 26000 CSR \& Integrated Management System (IP IMS), Community Development, Proper 
Beyond Complience, Capacity Building Perencanaan dan Pendampingan CSR wilayah Ring I dan Ring II PT Indonesia Power Semarang PGU, tersertifikasi Auditor Sistem Manajemen Pengamanan dan ISO 2800 Supply Chain Security Management System, Pengelola Keamanan dan Penanggulangan Bencana.

\section{Agus Naryoso}

Adalah Dosen pada Prodi D3 Hubungan Masyarakat Program Studi di Luar Kampus Utama Batang, Universitas Diponegoro, menjabat sebagai Ketua Program Studi, mengajar pada mata kuliah konsentrasi Public Relations, Public Speaking, Kampanye Public Relations, Kampanye Politik dan Corporate Social Responsibility, selama kurang lebih sepuluh tahun terkahir mempunyai fokus penelitian bidang CSR antara lain Analisis Kegiatan CSR Perusahaan di Indonesia dalam konteks Negara Rawan Bencana, Kualitas Program CSR dengan Reputasi perusahaan, selain itu juga menjadi trainer public speaking, CSR dan Community Development, PR, Manajemen Krisis, Strategi Komunikasi 